УдК 373

DOI: 10.21209/2658-7114-2021-16-2-59-69

\section{Александра Ивановна Улзытуева', доктор педагогических наук, доцент, Забайкальский государственный университет (672039, Россия, г. Чита, ул. Александрово-Заводская, 30), e-mail: alendra29@mail.ru, https://orcid.org/0000-0003-0998-0327}

Алла Викторовна Курганская", кандидат фрилологических наук, доцент, Забайкальский государственный университет (672039, Россия, г. Чита, ул. Александрово-Заводская, 30), e-mail: kurganskaya_alla@mail.ru, https://orcid.org/0000-0003-3658-117X

\section{Развитие умений анализа художественного произведения у детей дошкольного и младшего школьного возраста}

В статье актуализируется проблема развития умений анализа художественного произведения у детей дошкольного и младшего школьного возраста, определяется значимость анализа произведений художественной литературы при решении задач приобщения детей к книжной культуре, фрормирования интереса к чтению детской литературы. Решение обозначенных задач возможно при сфрормированности у педагогов дошкольного и начального общего образования методической компетенции, проявляющейся в знании особенностей произведений фрольклора и художественной литературы, в умении их анализировать. С целью выявления сформированности методической компетенции педагогам дошкольных образовательных организаций и средних общеобразовательных школ были предложены анкеты, результаты анкетирования представлены в статье. Выявлено, что педагоги осознают важность анализа художественных произведений, знают методы и приёмы анализа произведений, объяснения незнакомых детям слов, умеют формулировать вопросы, выявляющие понимание содержания произведения и др. Однако не всегда правильно определяют, на каком этапе знакомства с художественным произведением уместно задавать вопросы разного характера, ориентированные на глубокий анализ произведения. Анализ анкет педагогов и непосредственные наблюдения за образовательной деятельностью детей и педагогов в детских садах и школах свидетельствуют о необходимости планомерной и систематической работы по повышению методической компетенции воспитателей и учителей начальных классов в области анализа художественных произведений.

Ключевые слова: анализ художественного произведения, дети дошкольного и младшего школьного возраста, методическая компетенция, методы и приёмы анализа художественного произведения, фредеральный государственный образовательный стандарт дошкольного образования, федеральный государственный образовательный стандарт начального общего образования

Введение. На современном этапе социального развития проблема приобщения человека, в том числе детей дошкольного и младшего школьного возраста, к художественной литературе остаётся одной из самых важных в образовательном пространстве.

${ }^{1}$ А. И. Улзытуева - основной автор, систематизировала теоретическую информацию о проблеме анализа художественного произведения в дошкольном образовании, провела анкетирование и обработала анкеты педагогов дошкольного образования с целью выявления методической компетенции в области анализа художественных текстов.

${ }^{2}$ А. В. Курганская описала особенности анализа художественных произведений в начальной школе, провела анкетирование и обработала анкеты учителей начальных классов с целью выявления методической компетенции в области анализа художественных текстов.
Чтение способствует расширению кругозора, пониманию окружающей нас действительности, своего внутреннего мира и формированию собственного отношения к поступкам других людей. Дети дошкольного и младшего школьного возраста ещё только начинают приобщаться к художественной 
литературе, знакомство с которой позволяет общаться в мире детских книг; она помогает детям осознать идеи, изобразительные средства детских произведений; помогает понять, что с помощью художественного слова раскрывается вся глубина художественного произведения. Осознанное чтение художественной литературы позволяет привить интерес у ребёнка к художественному слову и к процессу чтения. В процессе чтения художественных произведений формируются нравственные представления у детей.

По нашему мнению, пониманию литературного творчества способствует анализ художественного текста, умение понять позицию автора и выразить собственное отношение к героям, их поступкам. В связи с этим развитие умения анализировать художественное произведение в дошкольном и младшем школьном возрасте - педагогическая проблема, требующая пристального внимания педагогов-практиков.

Цель данного исследования заключается в актуализации проблемы анализа произведений фольклора и художественной литературы при реализации образовательной области «Речевое развитие» в ДОО и на уроках литературного чтения в начальной школе.

Задачи исследования:

1) определить значимость анализа произведений художественной литературы при решении задач приобщения детей дошкольного и младшего школьного возраста к книжной культуре, формирования интереса к чтению детской литературы;

2) провести анкетирование с целью выявления сорормированности методической компетенции у педагогов дошкольных образовательных организаций и средних общеобразовательных школ;

3) выполнить анализ анкет педагогов дошкольного и начального общего образования, сформулировать выводы по исследуемой проблеме.

Методология и методы исследования. Методологической основой данного исследования являются системный (А. А. Богданов, Г. Саймон, П. Друкер, А. Чандлер) и деятельностный подходы (Л. С. Выготский, С. Л. Рубинштейн, А. Н. Леонтьев, В.В.Давыдов, Д. Б. Эльконин, П. Я. Гальперин, Н. Ф. Талызина и др.) к организации образо- вательной деятельности детей дошкольного и младшего школьного возраста. При реализации данных подходов на первый план выдвигается деятельность участников образовательных отношений (педагогов и детей), которая осуществляется в определённой системе. Основной целью реализации обозначенных подходов является развитие способностей ребёнка к продуктивной деятельности в разных социальных, образовательных, коммуникативных и других ситуациях. В нашем случае - к образовательной деятельности в процессе анализа художественных произведений. Обращение к системному и деятельностному подходам в профессиональной деятельности педагогов является важным с позиции эфффективного выполнения трудовых фрункций «Обучение» и «Воспитание».

Методы исследования: анализ, обобщение, систематизация результатов научных исследований в области анализа художественного текста в дошкольном образовании и начальной школе, анкетирование.

Результаты исследования и их обсуждение. В психолого-педагогической литературе понятие «методической компетенции» трактуется как совокупность методических знаний, умений, а также личностных качеств педагога. Опираясь на данное понятие, мы рассматриваем методическую компетенцию в области анализа произведений художественной литературы как знание методики ознакомления с художественной литературой; умение анализировать содержание произведений фрольклора и художественной литературы и определять значимость художественно-изобразительных языковых средств; сформированность у педагога читательской самостоятельности. На основании данного определения нами разработаны анкеты с целью выявления уровней сорормированности методической компетенции педагогов дошкольного и начального общего образования.

Обратимся к рассмотрению особенностей анализа художественного текста дошкольниками.

Гуманистическая направленность дошкольного образования, являющаяся основой во ФГОС ДО, проявляется и в содержании литературного образования детей. К задачам образовательной области «Речевое развитие» относятся знакомство с книжной 
культурой, детской литературой, понимание на слух текстов различных жанров детской литературы ${ }^{1}$.

Задачи образовательной области «Художественно-эстетическое развитие» включают становление эстетического отношения к окружающему миру, фрормирование элементарных представлений о видах искусства, восприятие музыки, художественной литературы, фольклора, стимулирование сопереживания персонажем художественных произведений ${ }^{2}$.

Перечисленные задачи ориентированы на формирование готовности к восприятию художественного материала детьми дошкольного возраста и анализу литературного текста как важному виду деятельности при ознакомлении с художественной литературой.

Процесс восприятия литературы рассматривается как особая психическая деятельность, заключающаяся в воссоздании авторских художественных образов. Психологами отмечается необходимость эмоционального наполнения всех видов детской деятельности, развития познавательного интереса к окружающему миру.

Развитие интереса к чтению - сложная педагогическая задача современного образования, в том числе и дошкольного.

Методика ознакомления дошкольников с произведениями фольклора и художественной литературы описана в трудах таких учёных, как М. М. Конина, Н. А. Флерина, Н. С. Карпинская, В.И. Логинова, О. С. Ушакова, Н. А. Стародубова и др. При этом особое место в воспитании любви к книге и подготовке будущего читателя в ДОО отводится развитию умения правильно воспринимать художественный текст. Данной проблеме посвящены работы Л. С. Выготского, С. М. Рубинштейна, И. А. Зимней, О. И. Никифоровой и др.

Говоря о развитии речи дошкольников, В. В. Запорожец отмечал, что оно тесно связано с формированием художественноречевой деятельности, которая является одной из важных частей эстетического воспитания детей дошкольного возраста. Например, при обучении пересказу фольклорных и литературных произведений дети знако-

\footnotetext{
${ }^{1}$ Федеральный государственный образовательный стандарт дошкольного образования: приказы и письма Минобрнауки РФ. - М.: Сфера, 2019. - 80 с.

2 Там же.
}

мятся с изобразительно-выразительными средствами художественного текста, такими как сравнения, эпитеты, синонимы, антонимы, метафоры и др. Овладение этими средствами позволяет лучше воспринимать художественное произведение [4].

Развитию речи и приобщению к художественной литературе способствует литературный анализ текста художественного произведения. Е. С. Тунгель отмечает, что «существует ложное представление о том, что текст анализировать не надо, что анализ разрушает, с одной стороны, художественную ткань произведения, с другой, - первичное восприятие, те эмоции, которые возникли у ребенка при ознакомлении с текстом» ${ }^{3}$. Однако именно анализ произведения учит детей понимать его логику и смысл, заостряет внимание на языковых средствах, помогает лучше понять поступки героев и т.д. Всё это требует от воспитателя не только сформированности методических компетенций, но и особого отношения к литературе как виду искусства.

Нами проведено анкетирование 43 педагогов ДОО с целью выявления отношения к анализу литературного произведения и знания отдельных методических вопросов, касающихся методики анализа произведения художественной литературы в процессе ознакомления с ним.

На первый вопрос анкеты (Какова цель анализа художественного произведения?) все педагоги выделили правильный ответ. На второй вопрос (Считаете ли Вы необходимым анализ художественного произведения при ознакомлении с ним детей?) только два воспитателя ответили, что анализ художественного произведения не следует проводить при ознакомлении с художественным произведением. Анкета не включала вопрос, позволяющий выразить мнение относительно отрицательного отношения к анализу произведения.

Остальные вопросы анкеты выявляли составляющие методической компетентности педагога. Известно, что анализ художественного текста в детском саду проводится посредством постановки вопросов. Умение правильно выслушать вопрос и ответить на него развёрнуто, в соответствии

${ }^{3}$ Тунгель Е. С. Анализ художественного текста. URL: https://sad-boltischki.schools.by/pages/analiz-hudoz hestvennogo-teksta (дата обращения: 15.03.2021). Текст: электронный. 
со смыслом - достаточно сложные умения для детей дошкольного возраста. В связи с этим педагог должен методически грамотно формулировать вопросы по тексту художественного произведения, учитывая возрастные возможности детей. Так, в старшем дошкольном возрасте рекомендуется задавать детям вопросы аналитического характера, однако на третий вопрос анкеты (Какие вопросы целесообразны при анализе литературного текста в старшей и подготовительной к школе группах?) 26 воспитателей ответили правильно (примерно 60,5%), остальные - не совсем верно (39,5 \%).

Педагоги дошкольных образовательных организаций назвали достаточно большое количество методов ознакомления с художественной литературой. Ответ на четвёртый вопрос (Перечислите, пожалуйста, методы ознакомления с художественной литературой) не вызвал затруднений, однако при ответе на него назывались на только методы, но и приёмы ознакомления с художественной литературой.

Важное значение при ознакомлении с произведениями фольклора и художественной литературы, а также в развитии лексической стороны речи детей имеет объяснение незнакомых слов, поскольку это обеспечивает и полноценное восприятие текста.

Методика объяснения незнакомых слов при ознакомлении с художественным произведением достаточно хорошо разработана. Так, описаны приёмы толкования значений слов, представлена уместность объяснения слов на том или ином этапе образовательной деятельности и т. д. В связи с этим, на наш взгляд, и пятый вопрос анкеты (Назовите, пожалуйста, приёмы объяснения незнакомых детям слов при ознакомлении с произведениями художественной литературы) не вызвал затруднений. В основном педагоги перечислили такие приёмы, как показ иллюстрации, замена слова синонимом или антонимом, объяснение слова через его состав, показ предмета или действия в естественных условиях, подстановка другого слова во время чтения, употребление слов или словосочетаний взрослым до чтения.

На шестой вопрос анкеты (Отличается ли беседа при чтении научно-популярной книги от беседы при ознакомлении со сказкой?) не все педагоги дали правильный ответ. Так, 19 воспитателей (44,2 \%) не видят отличий в анализе произведений разных жанров. Это не может не вызывать тревогу, так как свидетельствует о недостаточной литературоведческой и методической осведомлённости.

На седьмой вопрос анкеты (Испытываете ли Вы трудности при анализе языка произведения?) все педагоги ответили, что не испытывают затруднений при анализе языка художественного произведения. Предполагаем, что такие результаты свидетельствуют не о высокой теоретической и методической подготовленности, а о возможном нежелании уточнять трудности, с которыми сталкиваются воспитатели, анализируя язык текста литературного произведения.

При ответе на восьмой вопрос анкеты (На каком этапе целесообразен анализ литературного произведения: а) после первичного чтения; б) после повторного чтения?) 36 педагогов (83,7 \%) ответили методически верно; 7 педагогов (16,3 \%) предположили, что уместнее проводить анализ произведения после первичного чтения, в то время как на данном этапе выявляется главным образом эмоциональное восприятие текста детьми.

Таким образом, по результатам анкетирования мы можем сказать, что у педагогов дошкольного образования методическая компетенция, касающаяся анализа художественного произведения, недостаточно сорормирована. Педагоги знают, что такое анализ произведения, методы, приёмы анализа, знают приёмы объяснения новых слов, проводят анализ произведения с дошкольниками, но отождествляют понятия «метод» и «приём», не видят отличий в анализе произведений разных жанров.

Наблюдения за организованной образовательной деятельностью в детском саду, ориентированной на ознакомление дошкольников с такими произведениями, как «Живая шляпа» Н. Носова, «Белый домик» Б. Житкова и «Берёза» С. Есенина, показали, что в основном беседы по анализу данных произведений были построены правильно, однако во всех группах воспитатели уделили недостаточно внимания анализу языка произведений разных жанров, развитию умения вычленять художественно-изобразительные средства, развитию умения понимать роль художественно-изобразительных средств в передаче мыслей и чувств автора произведения и его героев. 
Формирование умения анализировать художественный текст продолжается на ступени начального общего образования. В Федеральном государственном образовательном стандарте начального общего образования отмечается, что в начальной школе закладываются основы фрормирования функциональной грамотности населения1. Для достижения данного результата необходимо формировать необходимость в систематическом чтении; соответствующий уровень читательской компетентности, общего речевого развития; расширять читательский кругозор; овладевать качествами навыка чтения (правильность, беглость, сознательность и выразительность), литературоведческими представлениями, методами и приёмами анализа художественного текста; развивать нравственные и эстетические чувства, читательские умения, способность к творческой деятельности и самостоятельности. При этом предмет «Литературное чтение» является средством личностного развития ученика и обеспечивает понимание литературы «как явления национальной и мировой культуры» [11].

В начальной школе на уроках литературного чтения обучающиеся под руководством учителя большое внимание уделяют художественному произведению, его идейной направленности, содержанию и форме [7]. Задачей педагога становится обучение младших школьников чтению и пониманию художественного произведения, помощь обучающимся в определении своего отношения к событиям, литературным героям, описанным в произведении [9, с. 56-57].

Исследованием проблемы, касающейся формирования умений анализировать художественное произведение, занимались М. С. Афронина, В. А. Левин, И. А. Кузьмина, Г. Ф. Гареева, А. Н. Андреев, Н. Н. Светловская, М. П. Воюшина и др. Данный вопрос остаётся актуальным, так как у младших школьников отмечается снижение интереса к чтению. В связи с этим многие исследователи говорят о необходимости обогащать образовательный процесс интересным содержанием, новыми формами и приёмами работы.

1 Федеральный государственный образовательный стандарт начального общего образования / Министерство образования и науки Российской Федерации. - М.: Просвещение, 2016. - С. 12.
Федеральный государственный образовательный стандарт начального общего образования предполагает развитие у обучающихся основных и пропедевтических умений при работе с художественным текстом ${ }^{2}$. К основным учебным умениям относятся умения, которые непосредственно связаны с анализом художественного текста: умение определять главную мысль и героев художественного произведения; умение устанавливать взаимосвязь между событиями, поступками героев, явлениями, фрактами, опираясь на содержание текста; умение находить средства выразительности (сравнение, олицетворение, метафору, эпитет); умение понимать текст, опираясь на содержащуюся в нём информацию, на жанр, структуру, язык; умение устанавливать связи, отношения, не высказанные в тексте напрямую; умение ориентироваться в нравственном содержании художественного произведения, самостоятельно делать выводы, соотносить поступки героев с нравственными нормами.

К пропедевтическим умениям, или умениям повышенного уровня, относят умение воспринимать художественную литературу как вид искусства; умение осмысливать эстетические и нравственные ценности художественного текста и высказывать суждение; умение определять, формулировать авторскую позицию, высказывать отношение к героям и их поступкам; умение отмечать изменения своего эмоционального состояния в процессе чтения литературного произведения; умение высказывать эстетическое и нравственноэтическое суждение и подтверждать высказанное суждение примерами из текста ${ }^{3}$.

Анализ художественного произведения многими исследователями рассматривается как сложный процесс, который представляет собой систему частных умений, направленных на постижение отдельных компонентов художественного произведения как частей художественного целого [8]. М. А. Рыбникова отмечает, что формирование умения анализировать художественный текст связано с воспитанием квалифицированного читателя, путь к которому, по её мнению, проходит через анализ произведения и через собственное литературное творчество обучающихся [по: 11, с. 18].

\footnotetext{
${ }^{2}$ Там же.

3 Примерная основная общеобразовательная программа начального общего образования / Министерство образования и науки РФ. - М., 2016. - С. 36-38.
} 
Методисты и учителя отмечают, что своеобразие анализа художественного текста зависит от характера, вида, жанра произведения, от особенностей восприятия произведения младшими школьниками [5, с. 341-342]. Анализ художественного произведения в начальной школе предполагает рассматривать в центре внимания сюжет произведения; его образность, авторское отношение к героям, их поступкам; нравственные проблемы, которые описывает автор [Там же].

Одной из особенностей восприятия художественного произведения младшими школьниками исследователи называют «наивный реализм». Художественное произведение воспринимается детьми как реальная действительность. Обучающиеся не могут определить фоорму произведения, авторский замысел, не могут назвать художественные особенности произведения. В начальной школе ученики проявляют два типа отношений к художественному миру произведений: эмоционально-образное непосредственная эмоциональная реакция, интеллектуально-оценочное, в котором присутствуют элементы анализа. Учитель помогает сохранять яркость восприятия, учит понимать идею художественного произведения ${ }^{1}$.

Ещё одна особенность восприятия художественного текста младшими школьниками - отсутствие потребности в перечитывании и анализе художественного произведения, поэтому учителю необходимо приучать обучающихся к более глубокому прочтению произведения.

Е. В. Посашкова выделила следующие умения, которые составляют умение анализировать текст:

- умение находить в тексте и анализировать изобразительно-выразительные средства художественного языка;

- умение видеть логику развития действия;

- умение описывать своеобразие характеров персонажей и средства их создания;

- умение формулировать позиции автора, рассказчика и героев;

- умение определять авторскую концепцию и т. д. [10].

${ }^{1}$ Андреев А. Н. Целостный анализ литературного произведения. - Минск: Электронная книга БГУ, 2008. $146 \mathrm{c}$.
При анализе изобразительно-выразительных средств художественного языка учителю необходимо научить не только находить эти средства выразительности (сравнение, эпитет, олицетворение и др.), но и определять их роль в художественном произведении ${ }^{2}$. Необходимо так продумывать вопросы к тексту, чтобы помочь обучающимся раскрыть красоту и содержательность этих средств выразительности. Например, можно задать следующие вопросы: «Почему автор выбрал именно эти слова? Какие чувства описывает поэт с их помощью?» ${ }^{3}$

Одним из сложных читательских умений является умение воспринимать образ-персонаж, т. е. эмоционально относиться к нему, сопереживать героям, радоваться с ними. На следующем этапе развития этого умения читатель учится умению определять особенности характеров и мотивы поведения героев произведения. Чтобы сформировать данное умение, нужно научить детей определять, какие художественные средства использует автор для создания образахарактера в произведении. В процессе фрормирования данного умения учитель использует методические приёмы, которые обусловлены особенностями художественных средств создания образа-персонажа ${ }^{4}$.

Формирование читательского умения определять идею произведения, понимать авторскую позицию является целью анализа художественного текста, без достижения которой анализ будет сухим и немотивированным логическим разложением сюжета произведения 5 .

Исследователи выделяют следующие приёмы анализа художественного текста, которые способствуют лучшему пониманию идеи произведения: словесное рисование; иллюстрирование эпизодов произведения, их анализ; стилистический эксперимент; подбор синонимов; составление диафильма, киносценария; чтение по ролям; инсценирование; составление рассказа о

${ }^{2}$ Рыжкова Т. В. Литературное развитие младших школьников: учеб. пособие. - СПб.: РГПУ им. А. И. Герцена, 2016. - 152 с.

${ }^{3}$ Посашкова Е. В. Формирование читательских умений младших школьников. - URL: http://www.deti-66. ru (дата обращения: 20.03.2021). - Текст: электронный.

${ }^{4}$ Рыжкова Т. В. Литературное развитие младших школьников: учеб. пособие. - СПб.: РГПУ им. А. И. Герцена, 2016. - 152 с.

${ }^{5}$ Сластенин В. А., Исаев И. Ф., Шиянов Е. Н. Педагогика: учеб. пособие / под ред. В. А. Сластенина. - М.: Академия, 2012. - 318 с. 
герое; пересказ от лица героев, музыкальное иллюстрирование произведения и др.

В процессе работы над художественным произведением учитель определяет вид анализа, виды работ над текстом, приёмы анализа, выбор которых зависит от особенностей художественного текста; от задачи, которую необходимо решить при анализе. Младших школьников необходимо обучать различным приёмам работы с текстом, таким как рисование словесных картин, составление плана рассказа, воссоздание в воображении образа, установление причинно-следственных связей [12, с. 42].

Работа над анализом в школе начинается с первого класса, при этом важно соблюдать преемственность с детским садом, где начинающие читатели ещё только знакомятся с художественными произведениями, расширяют свой читательский кругозор. В начальной школе обучающиеся изучают художественные особенности языка разных писателей и определяют направления работы с художественным текстом. В связи с этим для них используется упрощённая схема анализа художественного произведения:

1. Тема текста (о чём текст?).

2. Проблема текста (какие вопросы затрагивает автор?).

3. Цель текста, основная идея (зачем автор написал текст?).

4. Средства, используемые автором для выражения идеи:

- заголовок;

- ключевые слова;

- структура текста;

- языковые средства (обоснование выбора автора) [1, с. 84].

Учитель направляет анализ текста таким образом, чтобы обучающиеся открывали что-то новое, чтобы читателю было интересно вести диалог, рассуждать, определять идею произведения, авторское отношение к его героям, их поступкам, высказывать свои эмоции, чувства после прочтения произведения [Там же].

Самый распространённый приём анализа в дошкольной образовательной организации и в начальной школе - постановка вопросов к тексту, его эпизодам. С помощью вопросов младшим школьникам, как и дошкольникам, легче понять смысл произведения, определить языковые особенности текста, лучше понять идейную направленность художественного произведения, т. е. проанализировать причинно-следственные связи, определить позицию автора и сформировать своё отношение к читаемому. В процессе поиска ответов на вопросы у каждого собственное представление об идее произведения [6].

Остановимся более подробно на следующем этапе работы над художественным текстом - его интерпретации, которая представляет собой определение и истолкование художественного смысла произведения. В процессе интерпретации соединяются первоначальные представления обучающихся об идее автора и итоги анализа.

Этап интерпретации отличается от этапа анализа художественного произведения тем, что анализ происходит от целого к частям, а при интерпретации понимание идёт от частей к целому. По мнению Т.В.Обласовой, интерпретация - творческое, сознательное желание читателей узнать смысл произведения в каждой его части ${ }^{1}$.

Полнота и глубина интерпретации художественного произведения зависит от того, насколько тщательно и глубоко будет проанализировано произведение, какие методы и приёмы анализа используются на уроке. В исследовании сущности идеи произведения, интерпретирования текста обучающиеся проводят творческую работу, в результате которой ими выдвигаются собственные версии, излагаются свои представления о художественном произведении ${ }^{2}$. В процессе интерпретации художественного текста обучающиеся выражают свои мысли по поводу изучаемого произведения, узнают замысел автора, таким образом пытаясь выйти за границы того, что напрямую сказано в тексте, что является показателем осмысления текста обучающимися.

Таким образом, необходимо вести целенаправленную работу по развитию умения определять идею художественного произведения, его сущность. При этом обучающиеся овладевают приёмами выразительного чтения, выполняют коммуникативные задачи, которые возникли в процессе чтения. В процессе обучения анализу художественного произведения дошкольники и младшие школьники используют приёмы выразительного устно-речевого общения при слушании и чтении текстов. У обучающихся возникают

1 Обласова Т. В. Умения школьников работать с информацией: учеб. пособие. - М.: Флинта, 2018. - 27 с.

2 Там же. 
трудности, касающиеся неумения анализировать, обобщать, определять причинно-следственные связи, делать выводы. В связи с этим важно учить школьников воспринимать художественное произведение полноценно, т. е. определять его идейное содержание, понимать позицию автора, демонстрировать своё отношение к героям произведения, к событиям, описанным в нём [3, с. 210].

В методике обучения анализу художественного текста нам близки позиции Н. Н. Светловской и Г. М. Первовой, которые считают, что учитель должен обладать умением развивать в каждом ребёнке его возможности и способности с помощью детской литературы [11]. По мнению Н. Н. Светловской, учитель во время урока литературного чтения сам должен уметь увидеть в произведении проблему, определить его идею и оформить её в виде педагогической задачи, уметь оценивать, прогнозировать, стимулировать личностное развитие обучающихся, диагностировать уровень их обученности [Там же, с. 12]. Г. М. Первова отмечает, что «мастерство учителя начинает проявляться при подготовке к уроку литературного чтения» [по: 3, с. 209]. Задача учителя при этом - «поддерживать естественный ход интеллектуально-эмоционального развития детей посредством точной организации и научного управления процессом чтения как общения с учётом специфики литературного учебного материала и законов восприятия искусства, постепенного увеличения самостоятельности в читательской деятельности детей» [Там же].

Таким образом, умение анализировать художественное произведение представляет собой творческое умение, которое предполагает готовность читателя определить идею произведения, авторское отношение к героям произведения, их поступкам, сорормулировать собственное отношение к прочитанному. По мнению М. П. Воюшиной, данное умение формируется только в творческой деятельности обучающихся, в процессе анализа художественного произведения [2, с. 189].

Нами проведено анкетирование 56 учителей начальных классов с целью выявления знаний методики проведения анализа художественного произведения в начальной школе. На первый вопрос анкеты, касающийся цели анализа художественного произведения, больше половины учителей $(63,4 \%)$ ответили правильно, указав, что цель анализа художественного произведения - понимание идеи произведения, авторского отношения к героям произведения, формирование собственного отношения к прочитанному. Учителя $(36,6 \%)$, которые неправильно ответили на вопрос, не учитывают, что кроме выявления темы и основной мысли произведения нужно формировать собственное отношение к произведению, персонажам, их поступкам.

Второй и третий вопросы анкеты выявляли знание учителями этапов анализа художественного произведения в начальной школе и двух типов отношений к литературным героям младших школьников. Ответы показали, что менее половины учителей $(45,8 \%)$ владеют методикой проведения анализа художественного произведения, соблюдают его этапы, учитывают отношение детей к литературным произведениям.

При ответе на четвёртый и пятый вопросы учителя перечисляли приёмы и методы, которые используются ими при анализе художественного произведения. Можно отметить, что все учителя назвали достаточно много методов и приёмов анализа, но некоторые из них $(32,4$ \%) отождествляют понятия «метод», «приём».

Шестой вопрос анкеты, который касался знания видов работ с текстом, не вызвал затруднений у учителей. Педагоги перечислили достаточное количество видов работ с текстом. Чаще всего в ответах учителей встречались следующие виды работ с текстом: чтение с остановками, словесное рисование, медленное чтение, чтение по ролям, дописывание концовки произведения и др.

При ответе на седьмой вопрос анкеты педагоги назвали трудности, которые испытывают обучающиеся при анализе художественного произведения, среди которых отметили следующие: трудности в определении смысла прочитанного, в структурировании информации, в выделении главного.

Наблюдения за образовательной деятельностью на уроках литературного чтения с произведениями разных жанров (рассказ, басня, сказка, стихотворение) показали, что в основном учителя проводят поверхностную беседу по содержанию произведения, уделяют недостаточно внимания языку литературного текста, анализу выразительно-изобразительных средств, определению по- 
зиции автора. На уроках 9 учителей $(16,1 \%)$ работа с произведениями разных жанров проводилась по одному плану. Это свидетельствует о том, что учителя недостаточно хорошо владеют методикой работы с произведениями разных жанров, не обладают в полном объёме лингвистическими знаниями.

Таким образом, по результатам анкетирования можно сказать, что у большей части учителей начальных классов методическая компетенция в области обучения анализу художественного произведения сформирована недостаточно. Педагоги владеют методикой проведения анализа художественного текста; знают методы, приёмы проведения анализа, виды работ с текстом художественного произведения.

Заключение. Проведённый нами теоретический и практический анализ проблемы развития умений анализа художественной литературы у детей дошкольного и младшего школьного возраста актуализирует необходимость совершенствования методической компетенции педагогов в данной области. Решение задачи совершенствования методической компетенции воспитателей детских садов и учителей начальных классов целесообразно как на уровне образовательных организаций, так и на курсах повышения квалификации. При этом особое внимание необходимо уделять не только методическим вопросам, но и углублению литературоведческих знаний педагогов. Недостаточная сорормированность методической компетенции в области анализа произведений фольклора и художественных произведений разных жанров негативно сказывается на приобщении дошкольников и младших школьников к книжной культуре и художественной литературе, на формировании и поддержании интереса к чтению.

Работа по анализу произведений литературы начинается в детском саду с младшего дошкольного возраста и продолжается на всём протяжении школьного обучения, следовательно, необходимо обеспечение преемственности в развитии умений анализа произведений художественной литературы.

\section{Список литературы}

1. Агафонова Г. Н. Развитие читательской компетенции младших школьников // Наука и образование: отечественный и зарубежный опыт. 2019. № 3. С. 83-87.

2. Воюшина М. П. Модернизация литературного образования и развития младших школьников. СПб.: Сударыня, 2007. 318 с.

3. Гареева Г. Ф. Проблемы анализа художественного произведения в школе // Вестник Башкирского университета. 2008. № 1. С. 209-219.

4. Запорожец В.В. Психология восприятия ребёнком-дошкольником литературного произведения // Избранные психологические труды. М.: Педагогика, 2009. 128 с.

5. Кубузова И. И. Методика обучения комплексному анализу художественного текста // Вестник Пятигорского государственного лингвистического университета. 2009. № 1. С. 341-344.

6. Кузьмина И. А. Особенности работы с текстом в начальной школе на уроках чтения // Муниципальное образование: инновации и эксперимент. 2014. № 4. С. 43-45.

7. Ларина О. С. Особенности работы над произведениями по теме детства на уроках литературного чтения в начальной школе // Вестник Адыгейского государственного университета. 2011. № 3. C. $115-124$.

8. Маранцман В. Г. Анализ литературного произведения в соотношении с читательским восприятием произведения: автореф. дис. ... д-ра пед. наук: 13.00.02. М., 1980. 47 с.

9. Никитина Л. П. Современные подходы к анализу художественного произведения на уроках литературного чтения в начальной школе // Начальная школа на пути совершенствования. 2009. № 5. C. $56-67$.

10. Посашкова Е. В. Формирование читательской культуры младших школьников на уроках внеклассного чтения (на материале авторской программы по внеклассному чтению) // Педагогическое образование. 2009. № 1. С. 76-82.

11. Светловская Н. Н. Обучение чтению и законы формирования читателя // Начальная школа. 2003. № 1. C. 11-18.

12. Урумашвили Е. В. Прагматические аспекты анализа художественного текста // Известия Волгоградского государственного педагогического университета. 2010. № 2. С. 40-44.

Статья поступила в редакцию 10.03.2021; принята к публикации 18.04.2021 
Библиографическое описание статьи

Улзытуева А. И., Курганская А. В. Развитие умений анализа художественного произведения у детей дошкольного и младшего школьного возраста // Учёные записки Забайкальского государственного университета. 2021. T. 16, № 2. C. 59-69. DOI: 10.21209/2658-7114-2021-16-2-59-69.

\author{
Alexandra I. Ulzytueva1, \\ Doctor of Pedagogy, Associate Professor, \\ Transbaikal State University \\ (30 Aleksandrovo-Zavodskaya st., Chita, 672039, Russia), \\ e-mail: alendra29@mail.ru, \\ https://orcid.org/0000-0003-0998-0327
}

Alla V. Kurganskaya², Candidate of Philology, Associate Professor, Transbaikal State University

(30 Aleksandrovo-Zavodskaya st., Chita, 672039, Russia), e-mail: kurganskaya_alla@mail.ru, https://orcid.org/0000-0003-3658-117X

\title{
Development of Skills for Analysis of Artwork in Children of Preschool and Primary School Age
}

The article updates the problem of developing the skills of analyzing a work of art in children of preschool and primary school age. The article defines the significance of the analysis of works of fiction in solving the problems of introducing children to book culture, forming interest in reading children's literature. The solution of the indicated problems is possible when teachers of preschool and primary general education have methodological competence, manifested in knowledge of the features of works of folklore and fiction, in the ability to analyze them. In order to identify the formation of methodological competence, teachers of preschool educational organizations and secondary schools were offered questionnaires, the results of the questionnaire are presented in the article. It was revealed that teachers realize the importance of analyzing works of art, know the methods and techniques of analyzing works, explaining words unfamiliar to children, are able to formulate questions that reveal an understanding of the content of the work, etc. However, it is not always correct to determine at what stage of acquaintance with an art work it is appropriate to ask questions of a different nature, focused on a deep analysis of the work. The analysis of teacher questionnaires and the direct monitoring of the educational activities of children and teachers in preschool educational organizations and schools indicate the need for systematic and systematic work to increase the methodological competence of primary school teachers and teachers in the field of analysis of works of art.

Keywords: analysis of artistic work, children of preschool and primary school age, methodological competence, methods and techniques of analysis of artistic work, federal state educational standard of preschool education, federal state educational standard of primary general education

\section{References}

1. Agafonova, G. N. Development of reading competence of junior schoolchildren in Science and education: domestic and foreign experience, no. 3, pp. 83-87, 2019. (In Rus.)

2. Voyushina, M. P. Modernization of literary education and development of junior schoolchildren: monograph. St. Petersburg: Sudarinya, 2007. (In Rus.)

3. Gareeva, G. F. Problems of an art work analysis at school in Bulletin of Bashkir University, no. 1, pp. 209-219, 2008. (In Rus.)

4. Zaporozhets, V. V. Psychology of the perception by a preschool child of a literary work. Selected psychological works. M: Pedagogyka, 2009. (In Rus.)

${ }^{1}$ A. I. Ulzytueva - the main author, systematized theoretical information about the problem of analyzing an art work in preschool education, conducted and processed questionnaires of teachers of preschool education in order to identify methodological competence in the field of analyzing artistic texts.

${ }^{2}$ A. V. Kurganskaya described the features of the art works analysis in elementary school, conducted and processed questionnaires of primary school teachers in order to identify methodological competence in the field of analysis of artistic texts. 
5. Kubuzova, I. I. Teaching methodology for complex analysis of artistic text in Bulletin of Pyatigorsk State Linguistic University, no. 1, pp. 341-344, 2009. (In Rus.)

6. Kuzmina, I. A. Features of working with text in elementary school in reading lessons in Municipality: Innovation and Experiment, no. 4, pp. 43-45, 2014. (In Rus.)

7. Larina, O. S. Features of work on the theme of childhood in literary reading classes in elementary school in Bulletin of the Adygea State University, no. 3, pp. 115-124, 2011. (In Rus.)

8. Marantsman, V. G. Analysis of a literary work in relation to the readership of the work. Dr. ped. sci. diss. abstr. M, 1980. (In Rus.)

9. Nikitina, L. P. Modern approaches to the analysis of artistic work in literary reading lessons in elementary school in Primary school for improvement, no. 5, pp. 56-67, 2009. (In Rus.)

10. Posashkova, E. V. Formation of the reading culture of junior schoolchildren in extracurricular reading lessons (based on the author's program for extracurricular reading) in Pedagogical education, no. 1, pp. 76-82, 2009. (In Rus.)

11. Svetlovskaya, N. N. Teaching reading and the laws of the formation of the reader in Elementary school, no. 1, pp. 11-18, 2003. (In Rus.)

12. Urumashvili, E. V. Pragmatic aspects of artistic text analysis in News of the Volgograd State Pedagogical University, no. 2, pp. 40-44, 2010. (In Rus.)

Received: March 11, 2021; accepted for publication April 18, 2021

\section{Reference to the article}

Ulzytueva A. I., Kurganskaya A. V. Development of Skills for Analysis of Artwork in Children of Preschool and Primary School Age // Scholarly Notes of Transbaikal State University. 2021. Vol. 16, No. 2. PP. 59-69. DOI: 10.21209/2658-7114-2021-16-2-59-69. 